\title{
POBREZA Y DEUDA EXTERNA
}

Dr. Juan Cueva Jaramillo

$\mathrm{E}$

I Ecuador conoce el endeudamiento desde lejanas épocas. En efecto la primera deuda fue contraída para afrontar los gastos de la guerra de la independencia. Sin embargo esa vieja deuda nunca fue tan pesada ni intolerable como ha llegado a ser la actual.

Es muy curioso observar que el gran endeudamiento ecuatoriano se produce justo el momento en que encontramos petróleo. El endeudamiento agresivo estuvo ligado al auge petrolero de los años 70. Los fondos excedentarios de que disponía el mundo en aquella época, crearon un endeudamiento muy pronunciado en los países pobres. En el año de 1982 la deuda externa de los llamados países del tercer mundo alcanzó la astronómica cifra de 626 mil millones de dólares, lo cual significa el triple de lo que alcanzaba la deuda en el año de 1976 y siete veces más de lo que representaba en el de 1971.

El Ecuador tenía una deuda externa total de 343 millones de dólares en 1972, es decir debía el 18,4\% del producto interno bruto. En 1999 la deuda se había incrementado en $4700 \%$, lo cual equivale a decir que era 48 veces mayor (160\% del PIB). En 1972 cada ecuatoriano al venir al mundo debía $\$ 50$, mientras en 1999, cada ecuatoriano debía ya $\$ 850$ al nacer. $^{1}$

En el año de 1999 el Ecuador declaró la moratoria unilateral y parcial al pago del servicio de los bonos Brady. Le correspondía pagar 98 millones de dólares y tan solo pudo pagar \$52 millones. El presidente de aquel entonces dijo textualmente "no es que no queremos pagar, es que no podemos".

* Ex Embajador del Ecuador en Francia, Coordinador Internacional de la Campaña Eugenio Espejo por el Libro y la Lectura

1 cfr. VALENCIA Eduardo, la Deuda Externa como causa de la violencia en el Ecuador, Quito, 2000. 
En efecto, durante el año de 1998, el Ecuador destinó el $45 \%$ de sus ingresos al pago de la deuda externa e interna. Este porcentaje crecía de año a año.

Se calcula que más de un millón y medio de ecuatorianos han abandonado el país para buscar trabajo en el exterior.

Al 31 de diciembre de 1998, la deuda externa alcanzó la cifra de 16 339 millones de dólares. Los aumentos anuales de la deuda no respondían a recursos frescos sino a la capacitación de intereses no pagados. Cada ecuatoriano debe hoy $\$ 1433$ cuando viene al mundo.

Los efectos producidos por la deuda externa han dado como resultado una sociedad muy inequitativa, en la que el aumento de la pobreza es inquietante.

El aumento del precio de petróleo en el mundo hizo que los países productores dispusieran de grandes sumas de dinero que fueron colocadas en bancos de los Estados Unidos, del Japón y de Europa. Para invertir tales depósitos, se abrieron líneas de crédito a la disposición de los países pobres con condiciones aparentemente favorables.

Los países subdesarrollados necesitaban realizar obras de infraestructura para mejorar su nivel de vida. Así es como los recursos obtenidos por la vía de la deuda externa se volvieron cada vez más grandes. El endeudamiento agresivo se convirtió en política en buena parte de los países del tercer mundo.

Muy pocos de esos recursos se usaron en combatir estructuralmente a la pobreza. A veces se usaron esos fondos para comprar armas obsoletas a los países industrializados. Las obras faraónicas crecieron por doquier. Parte de los recursos fueron a parar en las manos de líderes corruptos que engrosaron las cuentas de bancos occidentales y de paraísos fiscales. La población pobre casi no se benefició en nada de este endeudamiento y, sin embargo, es la que está pagando la deuda externa a costa de su salud, su sudor y su miseria. 


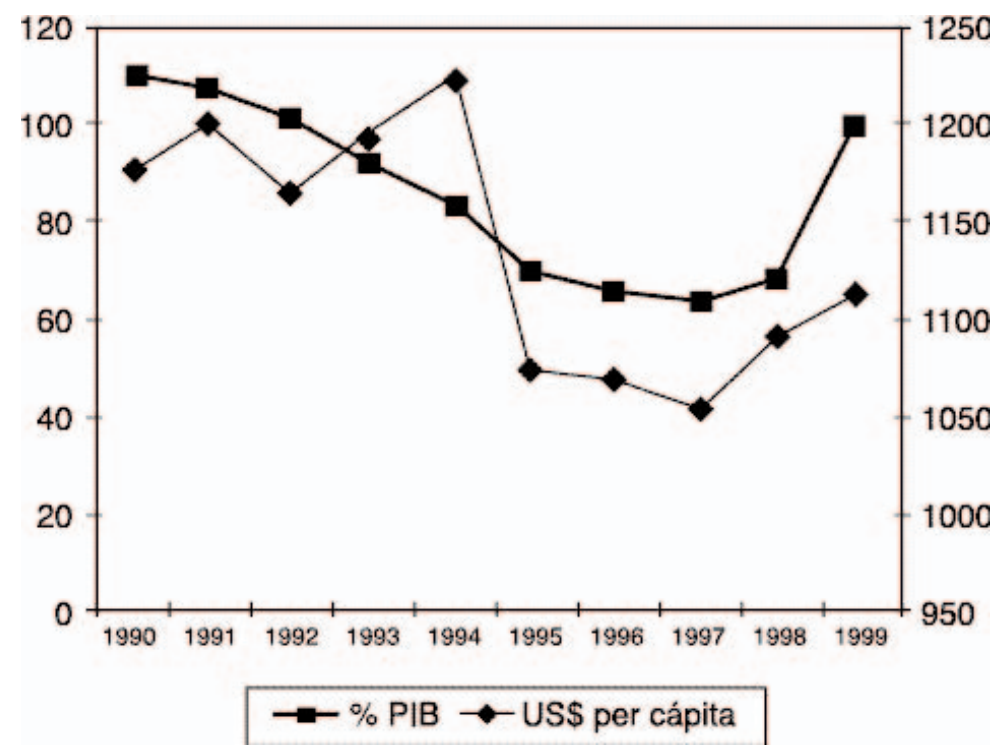

Indicador: Saldo final de la deuda externa pública expresado como porcentaje del PIB y per cápita.

Fuente: Banco Central del Ecuador. Información estadística mensual, 1990 - 1999.

A partir de 1980 los países industrializados comienzan a presionar al tercer mundo para que cumpla el pago de la deuda externa. Con frecuencia dichos países no tenían recursos ni siquiera para cubrir el servicio de la deuda y, de esta manera, contrataron nuevos emprésitos para pagar los intereses de la deuda que crecía como una bola de nieve. Cada vez más intereses para pagar intereses. La deuda externa se fue convirtiendo poco a poco en deuda eterna.

Estos nefastos efectos golpean sobre todo a las clases menos favorecidas de los países pobres del mundo. Los países pagan un porcentaje cada vez más grande de su producto interno bruto por el servicio de la deuda. El gasto social disminuye, los hospitales estatales no disponen ni de equipos ni de medicinas, las escuelas no tienen el equipamiento básico necesario, los apoyos a la agricultura desaparecen. El resultado es una gran inestabilidad política. La pobreza creciente da como resultado el aumento de la migración sur-norte.

Los programas de ajuste estructural son una consecuencia de esta situación mundial. Se trata de políticas hechas para lograr el pago de la deuda externa sacrificando su nivel de vida y su desarroIlo social. 
Sin la aceptación de estos programas de ajuste estructural, los países no logran acuerdos internacionales. Su aislamiento les conduce a una pobreza cada vez mayor. Nuevos préstamos son hechos solamente si es que los países aceptan estos programas de ajuste.

El aumento del desempleo y la disminución del gasto social son efectos que se sienten entre los pobres. Las restricciones de crédito afectan a las empresas pequeñas y medianas, conducen a la quiebra a los pequeños agricultores, mientras la liberación de los aranceles hace que las mercancías importadas sean más baratas que las nacionales, destrozando así la incipiente industria nacional.

El deseo de incrementar las exportaciones acelera a menudo la destrucción de los ecosistemas por medio de las plantaciones intensivas.

Los acreedores pueden ser bilaterales o multilaterales. También existen los acreedores comerciales que generalmente son bancos privados. Se han ensayado estrategias diferentes para resolver la crisis de la deuda pero ninguna ha dado resultados positivos. La idea ha sido siempre que las estrategias favorezcan a los acreedores. Las naciones deudoras han perdido buena parte de su soberanía al tratar de resolver el problema. Tan solo existen carteles de acreedores, pero nunca se ha permitido la creación de un cartel de deudores. La negociación siempre es de país a país o de organismo financiero multinacional con un país determinado, jamás con un grupo de países.

Los grandes capitales que han llegado a nuestro país a través de la deuda externa, no han servido sino en mínima parte para lograr un desarrollo social, han servido más bien con excesiva frecuencia para acrecentar la riqueza de muy pocos, mientras la pobreza se ha extendido como una plaga por amplios sectores de la sociedad ecuatoriana.

\section{DESARROLLO HUMANO}

\section{Desarrollo humano global.}

Durante mucho tiempo se consideró que el desarrollo humano era asimilable al crecimiento económico, pero actualmente se ubica a este último como un componente de aquel. Es decir que el desarrollo humano va mucho más allá del simple crecimiento. 
El nuevo concepto, desarrollado sobretodo por el Programa de la Naciones Unidas para el Desarrollo (PNUD) y otras agencias de las Naciones Unidas, ha producido un profundo cambio en el concepto básico del desarrollo. Este concepto toma las potencialidades de la persona como el objetivo último del desarrollo, estableciendo que el crecimiento económico es tan solo un medio para expandir la potencialidad del ser humano.

Al aceptar que no es suficiente el crecimiento económico para alcanzar el desarrollo, hay que integrar a otras dimensiones de lo social, tales como la satisfacción de necesidades básicas en salud, vivienda, educación, acceso a empleo, todo lo cual conduce a la disminución de las inequidades sociales al mismo tiempo que plantea una participación consciente del individuo en las decisiones sociales, como algo inherente al desarrollo. De esta manera se supera aquella concepción economicista que privilegiaba las estrategias económicas sobre las políticas sociales.

Para lograr un desarrollo humano verdadero, tenemos que reconocer el papel fundamental del sector público sobre las fuerzas del mercado y su libre accionar. Frecuentemente se han profundizado las desigualdades sociales al dejar sin ningún control a las leyes del mercado, así es como se ha acentuado la marginación de amplios sectores de población en los países subdesarrollados.

Otra idea nueva es el haber incorporado la noción de sustentación al analizar el desarrollo humano. En efecto el alto desarrollo tecnológico indiscriminado ha conducido a un deterioro creciente de los ecosistemas y de los recursos naturales. Algunos fenómenos de nivel mundial, como por ejemplo la pérdida de la biodiversidad y el efecto invernadero, han conducido a desarrollar el concepto de desarrollo humano sustentable, que es aquel en que se toma en cuenta al medio ambiente y su conservación al analizar las tendencias del desarrollo.

Esta nueva concepción es mucha más extensa y cubre aspectos antes olvidados al tratar de lograr un desarrollo humano justo y global.

A pesar de este avance teórico, en la realidad cotidiana vemos como avanza la inequidad social, persiste y aumenta la pobreza, se 
agranda la indigencia, se deterioran las condiciones de empleo y se produce un desmejoramiento ambiental en buena parte del planeta. Las zonas más afectadas coinciden con el llamado tercer mundo o mundo del subdesarrollo.

Según los datos más recientes dados a conocer por el Banco Mundial en Davos (Enero 30 de 2001) el diez por ciento de la población mundial recibe el $70 \%$ de sus ingresos totales y produce el $70 \%$ de sus bienes y servicios.

Por contraste casi la mitad de la población mundial vive con menos de dos dólares al día. Estos 3000 millones de personas producen apenas el $6 \%$ de la producción mundial. Es la pobre una quinta parte de la población del planeta, es decir 1200 millones de personas viven con menos de un dólar diario. Es la indigencia.

Mientras esto sucede, la tasa de ingresos promedio en los 20 países más ricos del mundo ha aumentado en 40 veces.

Según el último informe de la ONU sobre Desarrollo Humano, Noruega encabeza la lista de 173 países, mientras el último puesto le corresponde a Sierra Leona. El informe dice que luego de Noruega están Suecia, Canadá, Bélgica y Australia. Ecuador ocupa el puesto 94. Veamos una síntesis de la lista. ${ }^{2}$

\begin{tabular}{|l|c|}
\hline \multicolumn{1}{|c|}{ PAÍ́ } & LUGAR \\
\hline Noruega & 1 \\
\hline Suecia & 2 \\
\hline Canadá & 3 \\
\hline Bélgica & 4 \\
\hline Australia & 5 \\
\hline EE.UU. & 6 \\
\hline Japón & 9 \\
\hline Suiza & 11 \\
\hline Argentina & 34 \\
\hline Chile & 38 \\
\hline Brasil & 73 \\
\hline Ecuador & 94 \\
\hline Guatemala & 120 \\
\hline Haití & 146 \\
\hline
\end{tabular}

2 AFP. Diario El Comercio. Jueves, 25 de julio del 2.002, Pág. A-10 


\section{Desarrollo Humano en el Ecuador}

El Ecuador logró un avance importante durante los años del boom petrolero, y su camino posterior fue de permanente descenso, hasta el punto de que en el año de 1999 nuestro país ocupaba el puesto 84 entre 162 países en cuanto al Índice de Desarrollo Humano. Tan solo Bolivia ocupa una posición inferior en América del Sur. Esto se explica por factores tales como una elevada inequidad social, un prolongado estancamiento económico y un retraso histórico con respecto a los otros países del continente.

El ingreso per cápita en el Ecuador representa apenas el $43 \%$ del promedio latinoamericano. Las cosas se han agravado a partir del año 1998, en que empieza la gran crisis en la cual todavía estamos inmersos.

En los años 80 el Ecuador termina su fase de crecimiento económico, debido sobretodo al petróleo y se encuentra ubicado entre los países más endeudados, con lo que inicia la llamada crisis de la deuda externa, que le lleva de ajuste estructural en ajuste estructural, con la aplicación de una política de apertura comercial y que dio además, enorme importancia a los productos de exportación. Los conflictos políticos han sido frecuentes. Baste citar que en el último quinquenio dos Presidentes de la República fueron derrocados: Abdalá Bucaram y Jamil Mahuad.

El producto per cápita en 1998 era similar al de 1982, con inversiones externas muy bajas, casi todas en el sector del petróleo. El gran peso de la deuda externa y el déficit fiscal, han sido taras permanentes que se han agudizado con el tiempo. Los daños causados por la corriente de El Niño en 1998, la caída de los precios internacionales del petróleo, el conflicto con el Perú, que fue resuelto definitivamente en 1998, han pesado considerablemente en la crisis económica que soporta nuestro país. En el año de 1999 el ingreso por habitante bajó en algo así como el 9\%. El sistema financiero se ha visto destrozado y se han transferido al Estado más de la mitad de los bancos del país.

Las exportaciones se vuelven imprescindibles en el modelo dolarizado, aunque en el caso del Ecuador su evolución no ha sido como esperábamos. Uno de los problemas de las exportaciones es 
su limitada diversificación: en efecto, dentro de los países de América Latina es el que exporta mayoritariamente productos primarios, principalmente petróleo, banano, camarones, café, cacao y flores, de los cuales ninguno muestra perspectivas muy favorables en el mediano plazo. Por ejemplo el camarón, afectado por la mancha blanca, muestra su vulnerabilidad ecológica. El petróleo, a pesar de la construcción del OCP, tiene reservas limitadas y su mezcla con crudos pesados hace que su precio baje dentro de la escala internacional.

Si bien el proceso de dolarización ha logrado muy lentamente un relativo control de la inflación, sus problemas son muchos. Una inflación residual ha hecho que el país tenga costos iguales o mayores que en los Estados Unidos de América, quitándole competitividad al sector exportador, lo que ha llegado a poner en peligro la capacidad de venta externa de nuestros productos.

Los costos de producción aumentan sustancialmente, en consecuencia los productos exportables son menos competitivos en comparación a otros países de la región que se manejan con monedas más débiles y cuyos gobiernos tienen la capacidad de manejar políticas monetarias.

La deuda externa del Ecuador es una de las más fuertes en América Latina. En el año de 1999 la deuda total alcanzó los 16102 millones de dólares, equivalentes al $118 \%$ del PIB. El peso de estas obligaciones hace que en el presupuesto nacional se reduzcan rubros tan fundamentales como la salud y la educación.

Algunos factores históricos explican la gran inequidad que sufre nuestra sociedad. Una elevada concentración de la tierra, la exportación de productos intensivos y mano de obra barata, han dado como resultado un tejido social asimétrico, convirtiéndose el Ecuador en uno de los países con mayores niveles de inequidad social dentro de América Latina. La pobreza no es pues un hecho reciente ni es el resultado de la escasez de recursos, sino más bien de las enormes diferencias entre pequeños grupos de población muy ricos y grandes, más desposeídos. El ingreso per cápita en el Ecuador de 1999 llegaba a 1310 dólares, suma que casi duplica la línea de pobreza que está en el límite de los 700 dólares. Por ello es que el Ecuador no está dentro del grupo de países susceptibles de que se les perdo- 
ne la deuda externa, pues no es un país pobre, sino una sociedad en donde la distribución de la riqueza es muy desigual.

Durante los años de auge petrolero, se produjo una redistribución del ingreso, sobre todo en las ciudades y a favor de los estratos medios que tuvieron un crecimiento acelerado. Los procesos de ajuste estructural posteriores han cambiado esa tendencia, que minimizaron a la clase media y aumentaron peligrosamente las áreas de pobreza.

Esta injusta distribución de la riqueza se agrava cuando analizamos el aspecto étnico, pues la población indígena es la que más sufre en su nivel de vida y en la insatisfacción de sus necesidades básicas. Asimismo la población negra es de las más afectadas.

En cuanto a la generación de empleo, el Ecuador muestra una tendencia a la subutilización de su fuerza laboral. La extensa población campesina y la expansión del sector informal urbano, han dado como resultado un subempleo creciente que es la expresión de un excedente laboral. Ni aun en épocas del boom petrolero, el empleo creció sustancialmente, mientras en el campo, la agricultura expulsó algo así como 100 mil asalariados, que produjo una fuerte migración rural-urbana.

La adopción de una tecnología intensiva en capital, favoreció al sector formal urbano, en detrimento de los sectores rurales.

En cuanto al empleo urbano, podemos afirmar que casi la mitad de los trabajadores sobrevivían apenas con empleos inadecuados, sobre todo en el sector informal, en el empleo doméstico o como trabajadores del campo migrados hacia las ciudades.

Aunque el analfabetismo se ha reducido sustancialmente, aún resta un $10 \%$. La calidad del sistema educativo nacional deja mucho que desear en todos sus niveles.

La mortalidad infantil y la desnutrición en niños menores de 5 años, mantienen niveles excesivamente altos. Treinta por mil es la tasa de mortalidad infantil y $27 \%$ la de desnutrición. La desnutrición crónica alcanzó el $41 \%$ en sectores rurales de la Sierra y el $58 \%$ entre la población indígena. 
La cobertura y la calidad de los servicios de salud pública son insuficientes. Para dar un ejemplo, mencionemos que entre 1994 y 1999 el $29 \%$ de los partos en el país se dieron en el domicilio de la madre y sin atención profesional alguna.

La carestía habitacional es también preocupante, pues según el censo de 1990, tan solo el $38 \%$ de los hogares ecuatorianos disponía de agua potable en su interior.

\section{Desarrollo Humano y ciudadanía.}

El desarrollo humano tiene una íntima relación con el fenómeno de la indigencia y la pobreza, lo cual repercute claramente en el fenómeno de la ciudadanía.

Para la construcción de una sociedad integrada por verdaderos ciudadanos, se deben profundizar los procesos de democratización, lo cual conducirá necesariamente a un alivio en los temas de pobreza e indigencia.

El concepto de ciudadanía se relaciona con los derechos y deberes, protecciones y garantías que las leyes de un Estado reconocen para sus habitantes. Se vuelve clarísima la relación entre pobreza y ciudadanía cuando se toca el tema de los derechos sociales, pues los pobres no acceden a un nivel de vida que garantice su salud, su alimentación y su vivienda.

Al analizar la realidad ecuatoriana tenemos que constatar que por desgracia la mayor parte de nuestra población no cumple sus obligaciones relativas a la ciudadanía. Temas como el pago de los impuestos, la contribución al bienestar colectivo, el respeto a las leyes y reglamentos no son por desgracia cumplidos por el conjunto de nuestra sociedad. No nos sentimos obligados en relación a los demás, ni a nuestra ciudad, ni menos aún a nuestro Estado. Un concepto de irresponsabilidad prima en las prácticas sociales generalizadas. La pobreza es uno de los factores que más conspiran contra el concepto cabal de ciudadanía.

La construcción de una sociedad verdaderamente democrática exige una contribución ciudadana activa, condición que no puede darse en el caso de aquella población marginada por motivaciones económicas. 
Deformaciones sociales muy fuertes afectan al Ecuador contemporáneo: la irresponsabilidad, la corrupción, el clientelismo y las prácticas políticas anticiudadanas, producen como resultado un avance de la pobreza, de la indigencia y de la iniquidad.

El concepto de ciudadanía responde a un carácter amplio que, por desgracia, no es frecuente en la sociedad nacional. Podríamos hablar de la existencia de una masa muy grande que no llega a nivel de ciudadanía, a la que podríamos llamara cuasi-ciudadanos.

No es posible hablar de ciudadanía sin la práctica del clásico enunciado según el cual los derechos de uno terminan donde comienzan los derechos de los demás.

La incapacidad de entender lo público como perteneciente a todos y no como carente de dueño, es una característica peligrosa en nuestra sociedad. En efecto hay quienes piensan que los recursos del Estado no tienen dueño, de lo cual se desprende una extensión de la corrupción.

La responsabilidad personal es un elemento constitutivo de la ciudadanía. Nadie debe reclamar derechos sin cumplir obligaciones.

Es indispensable avanzar hacia una sociedad que descarte la idea de un Estado asistencialista. Cada uno de los habitantes debe ser responsable con su propio destino, y robustecer así la organización de la sociedad para alcanzar un nivel de verdadera ciudadanía. Para ello es indispensable que la comunidad cuente cada vez con menos marginados, es decir que los niveles de pobreza e indigencia diminuyan sustancialmente.

\section{Desarrollo Humano y medio ambiente}

En el año de 1882 el geógrafo Teodoro Wolf describió al Ecuador como un mendigo sentado en una montaña de oro. En efecto el país es poseedor de una gran riqueza en recursos naturales, pero el modelo de crecimiento económico basado en la explotación de recursos naturales para dedicarlos a la exportación, atenta contra la sustentación y crea factores negativos sobre el medio ambien- 
te, al tiempo que deteriora la gran riqueza de biodiversidad. Por ejemplo la explotación maderera y la deforestación en la Amazonia.

El modelo actual es el de crecimiento económico sustentado en la explotación de mano de obra barata y destinado al sector externo, lo que acelera los desequilibrios sociales y deteriora el medio ambiente. Tal es el caso de la exportación de petróleo, banano, palma africana, camarón, flores y hortalizas producidos expresamente para el mercado externo.

El medio ambiente es un recurso de salud para el pueblo. La contaminación deteriora la calidad de vida de toda la población y por lo tanto acelera los márgenes de pobreza y de indigencia.

Algunos modelos de desarrollo agrícola conducen necesariamente al deterioro del medio ambiente. Eso ocurre cuando se privilegia exclusivamente la rentabilidad en el proceso de producción, que conduce fatalmente al monocultivo, a la deforestación, al sobrepastoreo, a la quema de pisos ecológicos, todo lo cual lleva a una disminución de la calidad de vida de la población.

La pobreza agrava la presión sobre el medio ambiente. La sobrepoblación en algunas regiones del país constituye ya un verdadero problema, aunque hay que reconocer que la densidad poblacional total es totalmente soportable.

La pobreza reduce la capacidad de las personas para dar una utilización sustentable a los recursos naturales, por lo que el Estado debe desempeñar un papel activo en un doble sentido: combatir la pobreza y conservar el medio ambiente. Este rol debe ser claramente regulador y basarse en políticas que eviten la depredación de los recursos naturales. 